\title{
RAPD Profile Analysis of Single and Multigrain Aman Rice (Oryza sativa L.) Varieties Available in Bangladesh
}

\author{
Shawon Mitra, Tahmina Islam, R. H. Sarker and M. Imdadul \\ Hoque
}

Plant Breeding and Biotechnology Laboratory, Department of Botany,

University of Dhaka, Dhaka-1000, Bangladesh

Key words: RAPD profile analysis, Single and multigrain aman, Rice varieties

\begin{abstract}
Genetic variation in 14 local Aman rice varieties of Bangladesh including single grain and multigrain rice was investigated at the DNA level by RAPD molecular typing. Fifteen random primers were initially screened against DNA from five individuals that generated highly reproducible RAPD fragments, which were then subjected to further population analysis. A total 191 RAPD fragments were generated with these primers and 153 (80.1\%) were polymorphic, which indicated high level of polymorphism existed within these populations. The size of amplified fragments ranged between 450 and $6000 \mathrm{bp}$. Pair-wise distance estimated the range of 0.03 to 0.59 between single and multigrain Aman rice varieties. Results illustrated the potential of RAPD markers to distinguish improved varieties and grain specificity at DNA level.
\end{abstract}

\section{Introduction}

Rice (Oryza sativa L.) is one of the most important cereal crops around the world, which provides the necessary daily calories and protein (15\%) for more than half of the world's population (Singh et al. 2012; Tyagi et al. 2004, Maclean et al. 2002). At least 114 countries grow rice and approximately $90 \%$ of the world's rice is grown in the Asia (Salim et al. 2003, Paranthaman et al. 2009). Over the last 1000 years, rice has been the dominant crop in Bangladesh and at least 1,000 traditional varieties cultivated per landraces (Hossain and Jaim 2009). Most of the rice varieties of Bangladesh are growing in the Aman season. It is the second largest growing season of the country in respect of the quantity of production. It is notable that the area coverage of Aman is the largest as a single crop which is approximately $51 \%$ of total land area (bbs.gov.bd). 
Recently a new Aman rice having a unique multigrain feature has been reported from Bangladesh (Krisoks' Weblog 2012). This unique rice has two or three grains within a seed. However, the reason behind the multigrain seed nature is still unknown due to lack of experimental reports on this aspect. The phylogenetic divergence of single- and multigrain Aman rice varieties of Oryza sativa L. is also not well understood. Under this circumstance, it is worth to characterize this unique rice variety and shed light on its evolutionary divergence pattern within and between other Aman rice varieties of Bangladesh. To find out the relationship and differences among the cultivars based on only morphological characters sometimes do not produce convincing conclusions. However, molecular markers provide information that helps in deciding the distinctiveness of species and their ranking according to the number of close relatives and phylogenetic position (Rahman et al. 2007). Several types of molecular markers are available for evaluating the extent of genetic variation in rice. These include RFLP (Botstein et al. 1980), RAPD (Williams et al. 1990), AFLP (Vos et al. 1995) and SSR (Tautz 1989). Of these RAPD markers are increasingly being employed in genetic research owing to its speedy process and simplicity (Williams et al. 1990). This technique always allows the examination of genomic variation without prior knowledge of DNA sequences (Hadrys et al. 1992). It is especially useful for unzipping the variations in species with low genetic variability when other techniques such as isozyme analysis fail to reveal differences among the individuals. Moreover, varietal distinctiveness and relativeness can unambiguously be estimated by RAPD fingerprinting in commercially important crops. Previously it was reported that the level of genetic differentiation between cultivars of $O$. sativa increased with geographical distance. The polymorphisms detected among the accessions are helpful in selecting genetically diverse cultivars in future breeding programme (Deepu et al. 2013). RAPD analysis also showed promise as an effective tool in estimating genetic polymorphism in different rice cultivars.

Traditional rice breeding has made significant progress towards higher yield, improved quality, greater disease resistance and other important agricultural characters in the past and even in future, it will still play an important role (Sun et al. 1990). With the growth of global population and the increasing demand for food, rice represents $27 \%$ of the dietary energy supply for the population in developing countries (Redoña and Mula 2004). To accommodate the increasing demand, new rice varieties with high yield potential and specific marker for the improvement of new variety is in much demand. To achieve this is goal, new strategic and innovative approaches are urgently needed. This study aimed at using RAPD markers to evaluate the genetic variation within a collection of local 
single- and multigrain Aman rice varieties and to reveal genetic relationships among them for future use in selection, hybridization, biodiversity assessment and conservation of diverse gene pools.

\section{Materials and Methods}

A total of 14 varieties of Aman rice used in this experiment are listed in Table 1. The seeds of 11 varieties (BRRI Dhan-33, 37, 39, 40, 46, 49, 51, 53, 57, 62 and Khajur Jhupi) were released by Bangladesh Rice Research Institute (BRRI), Gazipur, Bangladesh. The rest of the three varieties are local of which Biram sundari and Double rice are multigrain (Fig. 1).

DNA extraction: Young, fresh leaves were collected from 25 days old pot grown seedlings to extract genomic DNA by cetyl trimethyl ammonium bromide (CTAB) method (Doyle and Doyle 1987). The leaves were washed in distilled water and ethanol and dried on fresh tissue paper to remove spores of microorganisms and any other source of foreign DNA. Four hundred mg leaf tissue taken in liquid nitrogen and grinded to fine powder then added $1.6 \mathrm{ml}$ extraction buffer ( $3 \%$ CTAB; $1.4 \mathrm{M} \mathrm{NaCl} ; 100 \mathrm{mM}$ Tris-HCl, $\mathrm{pH} 8.0 ; 20 \mathrm{mM}$ EDTA, pH 8.0 and $0.2 \%$ mercaptoethanol). The homogenous paste transferred to an Eppendorf tube $(2.0 \mathrm{ml})$ and incubated at $60^{\circ} \mathrm{C}$ in a water bath for $30 \mathrm{~min}$. The samples were centrifuged at $13,000 \mathrm{rpm}$ for $10 \mathrm{~min}$ at $4^{0} \mathrm{C}$ then equal volume of chloroform : isoamyl alcohol $(24: 1)$ was added with the supernatants and centrifuged the tubes at $13,000 \mathrm{rpm}$ for 10 minutes. The supernatant with $2 / 3$ vol. chilled isopropanol was kept for overnight at $-20^{\circ} \mathrm{C}$ to precipitate the DNA. The supernatants were discarded carefully after centrifuged for $10 \mathrm{~min}$ at 13,000 rpm and DNA pellet was collected. The pellet was washed with $70 \%$ ice-cold ethanol and air dried. The dried DNA was dissolved in $50 \mu \mathrm{l}$ of TE buffer and treated with RNase A for $30 \mathrm{~min}$ at $37^{\circ} \mathrm{C}$ and store at $-20^{\circ} \mathrm{C}$. The concentration of DNA was estimated with Nanodrop.

DNA amplification: For RAPD analysis 15 decamer primers were applied which had 60 or $70 \%$ of $G+C$ content. Twenty five $\mu$ reaction mixture contains $2.5 \mu \mathrm{l} 10 \times$ Taq DNA buffer, $100 \mu \mathrm{M}$ dNTPs, $1 \mu \mathrm{M}$ primer, $1 \mathrm{U}$ Taq polymerase (Thermo-scientific) and $50 \mathrm{ng}$ genomic DNA. PCR amplification mixture maintained at $0^{\circ} \mathrm{C}$ during its preparation. The PCR amplification mixture placed in a thermal cycler (Applied Biosystems) with the following thermal cycling conditions, these were one cycle of $94^{\circ} \mathrm{C}$ for $5 \mathrm{~min}, 35$ cycles of $94^{\circ} \mathrm{C}$ for 45 seconds, 32 or $34^{\circ} \mathrm{C}$ for 30 seconds, and $72^{\circ} \mathrm{C}$ for $3 \mathrm{~min}$ then one cycle of $72^{\circ} \mathrm{C}$ for 7 min. After completion of cycling programme, the reactions were held at $4^{\circ} \mathrm{C}$. 
Table 1. List of selected Aman rice varieties used in the genetic analysis.

\begin{tabular}{cll}
\hline Sl. & Name of varieties & Source \\
\hline 1 & Khajur Chori (Acc. No. 4795) & Khulna, Sadar (BRRI) \\
2 & Khajur Jhupi (Acc. No. 2551) & BRRI Breeding Line \\
3 & Double Rice (Acc. No. 3905) & Tangail, Sadar (BRRI) \\
4 & Biram Sundari & Birampur, Dinajpur (PB \& B Lab. DU) \\
5 & BRRI Dhan 33 & $"$ \\
6 & BRRI Dhan 37 & $"$ \\
7 & BRRI Dhan 39 & $"$ \\
8 & BRRI Dhan 40 & $"$ \\
9 & BRRI Dhan 46 & $"$ \\
10 & BRRI Dhan 49 & $"$ \\
11 & BRRI Dhan 51 & $"$ \\
12 & BRRI Dhan 53 & $"$ \\
13 & BRRI Dhan 57 & $"$ \\
14 & BRRI Dhan 62 & $"$ \\
\hline
\end{tabular}

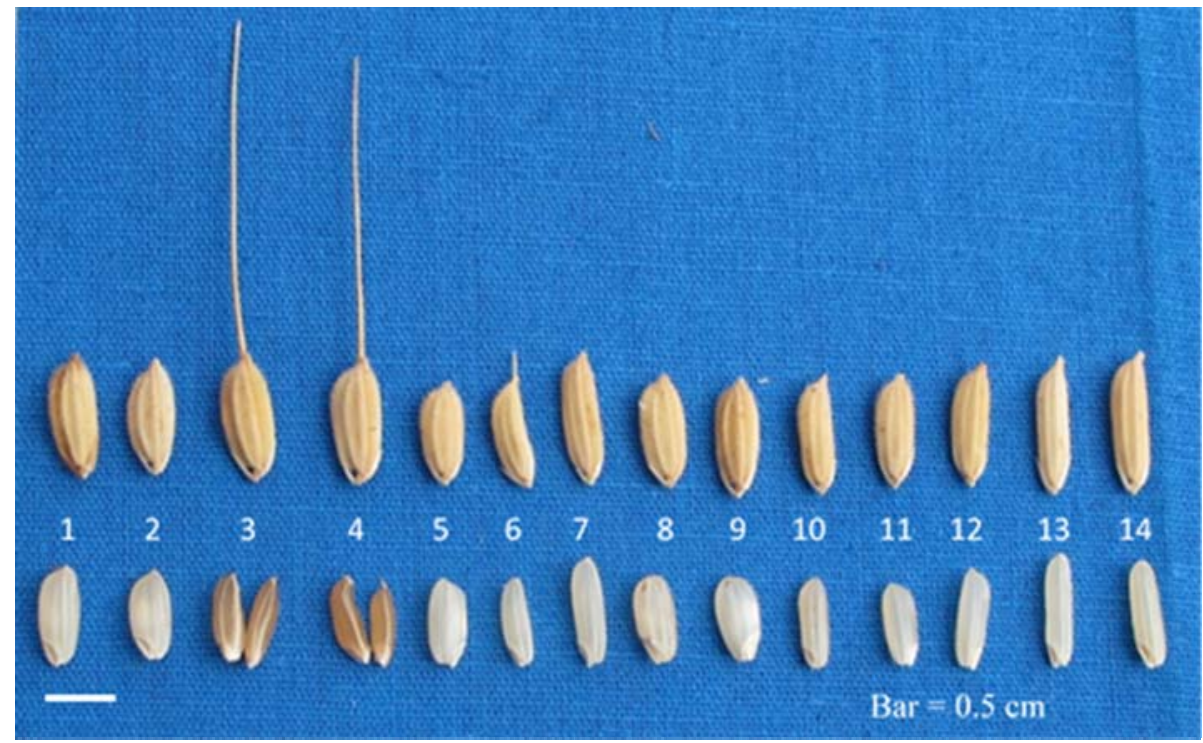

Fig. 1. Seeds and grains of different Aman rice varieties used in the present investigation. Identification of varieties (1 - 14) is shown in Table 1. 
The amplified products were separated electrophoretically on $1 \%$ agarose gel with $1 \times$ TAE buffer and ethidium bromide. Agarose gel electrophoresis was conducted in $1 \times$ TAE buffer at 90 volts and $250 \mathrm{~mA}$ for $45 \mathrm{~min}$. One molecular weight marker $1 \mathrm{~kb}$ plus or $1 \mathrm{~Kb}$ DNA ladder (GeneRuler ${ }^{\mathrm{TM}}$ ) was electrophoresed alongside the amplified product. Gel was photographed by using UV Transilluminator (Cleaver Scientific Ltd.).

\section{Results and Discussion}

The genetic diversity and the relationship among 14 Aman rice genotypes were evaluated by using 15 primers. Initially 20 primers were tested and out of them, 15 primers that gave rise to amplified products were selected for evaluating genetic relationship of rice cultivars (Table 1). Figs 2 and 3 are presented to present the amplification profiles generated with the primers across 14 single grain and multigrain rice varieties. A considerable level of variability was observed among different cultivars. A total of 191 reproducible and scorable amplification products were generated across 14 varieties (Table 2) and these were in the size range of 450 to $6000 \mathrm{bp}$. The number of amplification products generated by each primer varied from 5 (OPB-9) to 23 (OPB-7) with an average of 12.7 bands per primer. Out of 191 bands, 153 (80.1\%) were found to be polymorphic for one or more cultivars ranging from 5 to 20 fragments per primer. Primers OPB-03 resulted in the highest percentage of polymorphic bands, while the minimum polymorphism was observed using OPA-3 primer. RAPD analyses in $O$. sativa accessions were also reported earlier (Muhammad et al. 2005, Rahman et al. 2007, Malik et al. 2008). RAPD markers also have been used to detect polymorphisms in different crops like maize 72.2\% (Carvalho et al.2004), wheat 49.12\% (Nimbal et al. 2009), canola 61\% (Moghaieb et al. 2014) and cabbage $84.44 \%$ (Saxena et al. 2011). In this investigation, banding pattern of primer OPB01, OPB02, OPB06, OPB07, OPB08, OPB11, OPB12, OPB14 and OPK08 were crucial for detecting and identifying polymorphism based in variety specific unique bands. Three multigrain varieties viz. Biram Sundari and Double rice specific unique bands were identified with primer OPB01 and OPK08 (Figs 2 and 3). The banding profiles of these multigrain containing rice varieties are clearly distinguishable from single grain containing rice variety, although they share similar pattern in banding profile within themselves.

A distance matrix based on the proportion of shared RAPD fragments was used to establish the level of divergence between and within the 14 Aman rice varieties. The Nei's distance matrix (Nei 1972) was employed to estimate the genetic distances among the varieties (Table 3). It was observed that the genetic 
distances were highly variable among 14 Aman rice varieties, ranged from 0.0373 to 0.5983 as revealed by the genetic distances matrix. Deepu et al. (2013) reported 0.19 - 0.54 genetic distances within Indian cultivars and Yeasmin et al. (2013) showed 0.088 - 0.504 within BRRI varieties. Garris et al. (2005) also found overall higher gene diversity for the indica group (0.55) and lower for japonica varieties (0.47). On the contrary, Thomson et al. (2007) reported as slightly higher index of

Table 2. Analysis of reproducible amplified loci with different RAPD primers within the rice varieties.

\begin{tabular}{ccccc}
\hline $\begin{array}{c}\text { Marker } \\
\text { ID }\end{array}$ & Sequence $\left(5^{\prime}-3^{\prime}\right)$ & $\begin{array}{c}\text { Total no. of } \\
\text { RAPD loci }\end{array}$ & $\begin{array}{c}\text { No. of polymorphic } \\
\text { RAPD loci }\end{array}$ & $\begin{array}{c}\text { Percentage of } \\
\text { polymorphism }\end{array}$ \\
\hline OPA02 & TGC CGA GCT G & 9 & 6 & 66.67 \\
OPA03 & AGT CAG CCA C & 9 & 5 & 55.56 \\
OPB01 & GTT TCG CTC C & 21 & 17 & 80.95 \\
OPB02 & TGA TCC CTG G & 16 & 15 & 93.75 \\
OPB03 & CAT CCC CCT G & 12 & 12 & 100 \\
OPB04 & GGA CTG GAG T & 9 & 6 & 66.67 \\
OPB05 & TGC GCC CTT C & 9 & 5 & 55.56 \\
OPB06 & TGC TCT GCC C & 15 & 9 & 60.0 \\
OPB07 & GGT GAC GCA G & 23 & 20 & 86.96 \\
OPB08 & GTC CAC ACG G & 12 & 9 & 75.0 \\
OPB09 & TGG GGG ACT C & 5 & 4 & 80.0 \\
OPB11 & GTA GAC CCG T & 12 & 11 & 91.67 \\
OPB12 & CCT TGA CGC A & 11 & 9 & 91.82 \\
OPB14 & TCC GCT CTG G & 17 & 16 & 81.82 \\
OPK08 & GAA CAC TGG G & 11 & 9 & \\
\hline
\end{tabular}

gene diversity for the japonica group (0.56), while the indica group was 0.54. Relatively high distance index was observed in 'BRRI Dhan-51' vs 'BRRI Dhan37', 'BRRI Dhan-53' vs 'BRRI Dhan-37', 'BRRI Dhan-53' vs 'Khajur chori', 'BRRI Dhan-57' vs 'BRRI Dhan-37' variety pairs comparing to the other cultivar pairs. The lowest distance index was observed in 'Biram sundari' vs 'Double rice' (0.03) (Table 3). Genetic distance was lowest between Biram sundari and Double rice that indicates close relatedness within multigrain varieties. This result exhibited two multigrain varieties were same or originated from the same origin or genetic variation between these varieties increased because of their geographical distance (Deepu et al. 2013). This result indicates that genotypic variation does 
not necessarily reflect in phenotypic characters (Cirillo et al. 2009). Out of 12 single grain varieties breeding line Khajur Jhupi, BRRI Dhan-46 and BRRI Dhan49 have low genetic distance with multigrain variety.

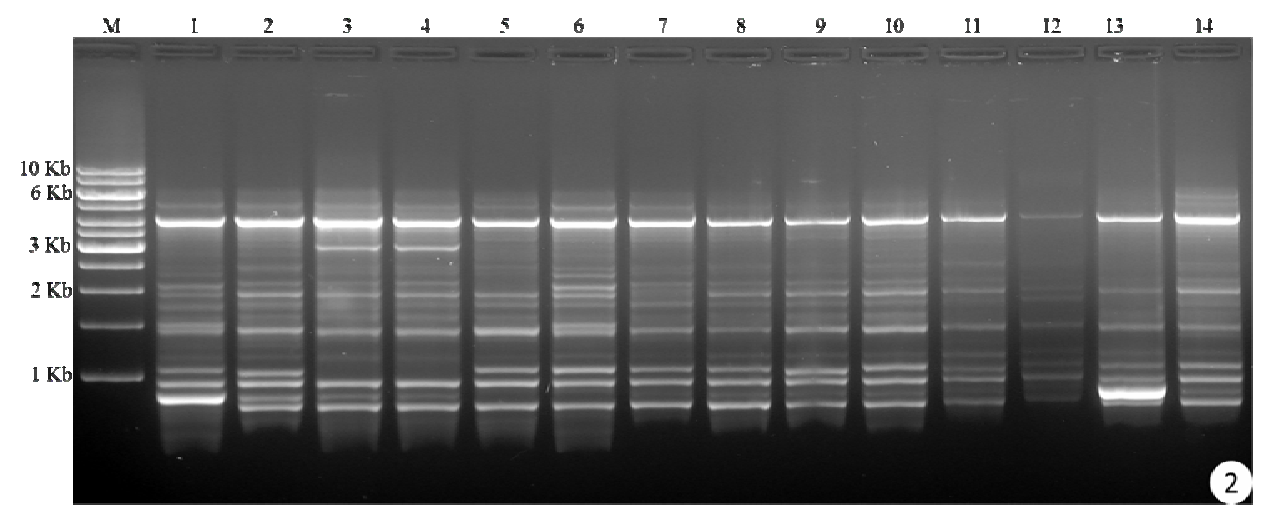

Fig. 2. RAPD profiles of the 14 Aman rice varieties with OPB-1 primer. Lane-M Ladder $(1 \mathrm{~Kb})$ and lane 1-14, amplified DNA of (1) Khajur Chori, (2) Khajur Jhupi, (3) Double Rice, (4) Biramsundari, (5) BRRI Dhan-33, (6) BRRI Dhan-37, (7) BRRI Dhan-39, (8) BRRI Dhan-40, (9) BRRI Dhan-46, (10) BRRI Dhan-49, (11) BRRI Dhan-51, (12) BRRI Dhan-53 (13) BRRI Dhan-57 and (14) BRRI Dhan-62, respectively.

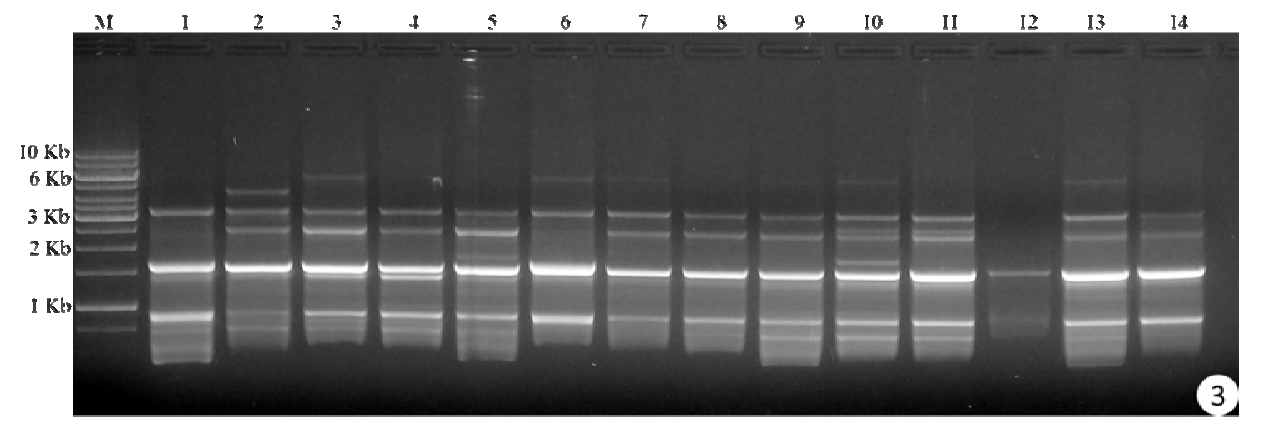

Fig. 3. Same as Fig. 2 but using OPK-8 primer.

Genetic distance obtained from RAPD data was used to create a cluster diagram. Cluster analysis based on Nei (1972) distance matrix using UPGMA grouped 14 Aman rice cultivars into 6 major clusters at the similarity coefficient of 0.44 (Fig. 4). Cluster I consisted of Khajur Chori and hybrid variety BRRI Dhan-37 indicating relatively less divergence among the cultivars of this cluster due to originating from closely related ancestors. Cluster 2 included two multigrain varieties Biram sundari, Double rice and inbred line Khajur Jhupi. In this cluster, the coefficient of distance ranged from 0.16 to 0.19 indicating high relatedness among the multigrain forming varieties. The remaining hybrid varieties that was released by BRRI were aggregated in clusters 3,4 and 5 . BRRI 


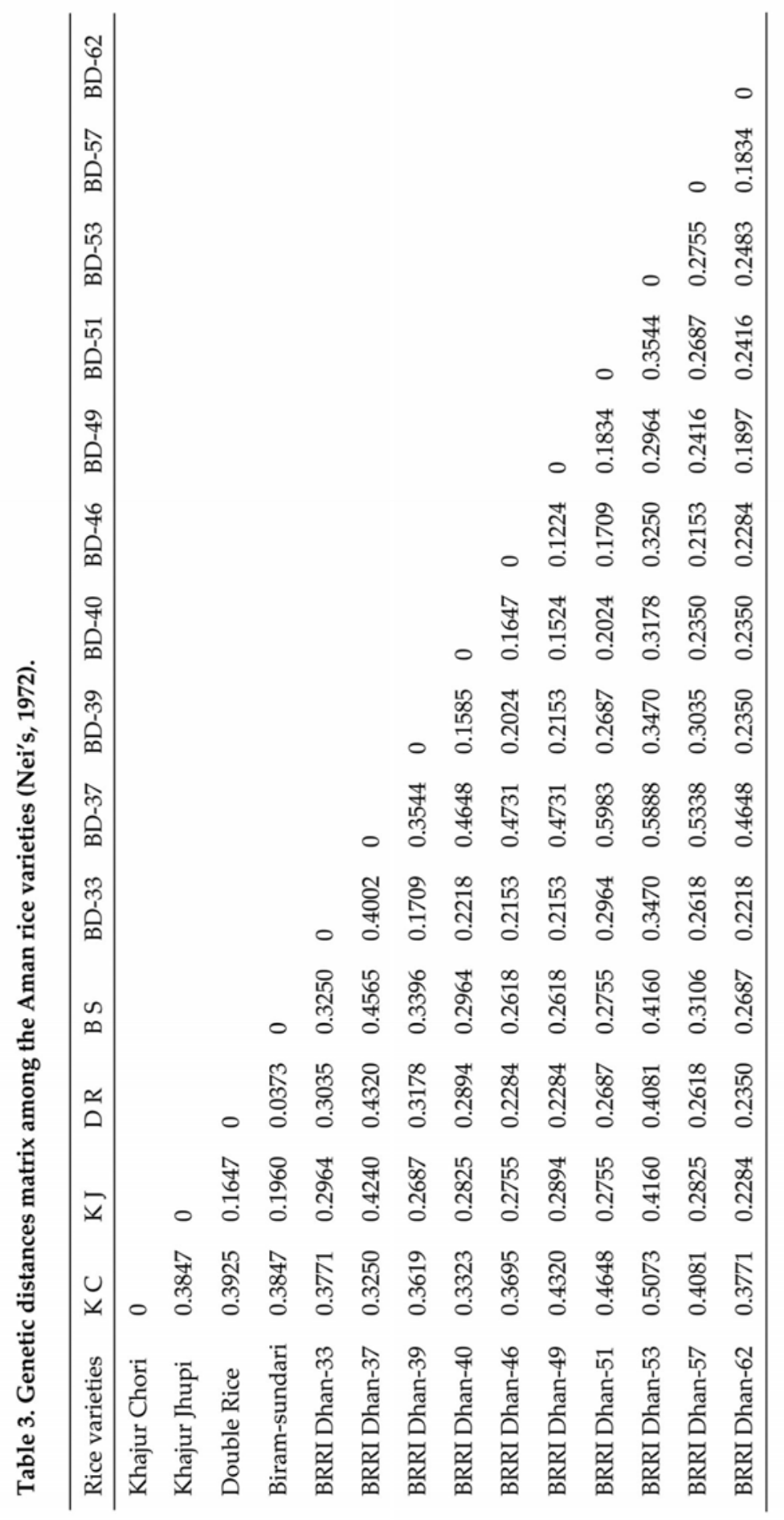


Dhan-33, BRRI Dhan-39 and BRRI Dhan-40 were grouped under the cluster 3. Cluster 4 included BRRI Dhan-46, BRRI Dhan-49 and BRRI Dhan-52. Cluster 5 included two varieties BRRI Dhan-57 and BRRI Dhan-62. Only one variety BRRI Dhan-53 included in cluster 6 which indicated more divergence. Crossing between the genotypes with high distance coefficient will manifest high heterosis. As regards to higher quality status of 'BRRI Dhan-53' among cultivars, it is essential that to pay more attention to it in hybridization programs.

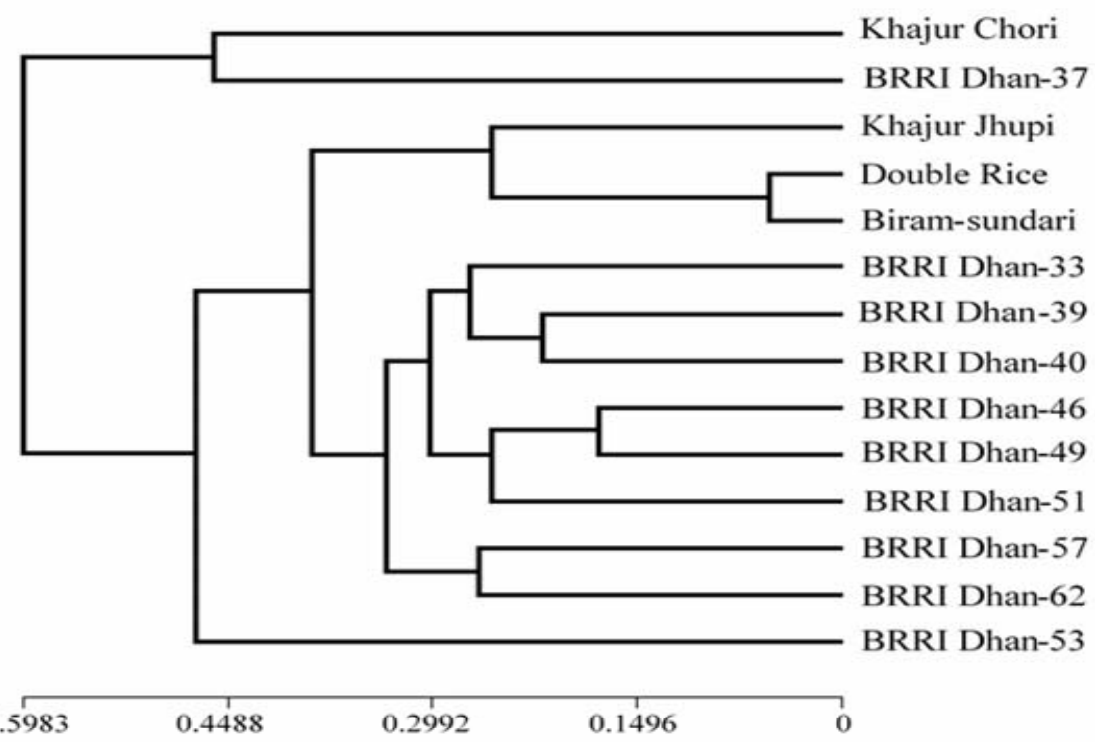

Fig. 4. UPGMA dendrogram of the unweighted pair group method with arithmetic averaging cluster analysis revealed by random amplified polymorphic DNA.

Through the present work it has been possible to find out the genetic variation and relatedness among the 14 Aman rice germplasm including single and multigrain features. Genetic variability is the key component for the successful crop improvement programme (Ravi et al. 2003). The employment of RAPD markers in genetic diversity analysis helped in grouping the genotypes. Cluster analysis based on the RAPD data revealed that although the morphology of multigrain varieties was same but they exhibited little genetic distance between them. In addition, the present study showed that cultivars in first cluster possess high degree of genetic similarity possibly due to originating from closely related ancestors. The results of the present investigation have opened up a possibility for developing a molecular genetic map that will lead to the application of marker assisted selection tools in genetic improvement of Aman rice. 


\section{Acknowledgements}

The authors gratefully acknowledge the Plant Breeding Division of Bangladesh Rice Research Institute, Gazipur, Bangladesh for providing the rice seeds and technical cooperation during the study. The seeds of Biram Sundari was provided by Rita Sarah Borna which is gratefully acknowledged.

\section{Reference}

BBS (www.bbs.gov.bd/)

Botstein D, White RL, Skolnick M, Davis RW (1980) Construction of a genetic linkage map in man using restriction fragment length polymorphisms. Amer. J. Hum. Genet. 32: 314-333.

Carvalho VP, Claudete F Ruas, Josué M Ferreira, Rosângela MP Moreira and Paulo M. Ruas (2004) Genetic diversity among maize (Zea mays L.) landraces assessed by RAPD markers. Genetics and Molecular Biology 27(2): 228-236.

Cirillo A, Gaudio SD, Bernardo GD, Galderisi U, Cascino A and Cipollaro M (2009) Molecular characterization of Italian rice cultivars. Eur Food Res Technol (2009) 228:875-881

Deepu V, Rajani J, Nair GM and Nair AJ (2013) Molecular characterization of selected cultivars of rice, Oryza sativa L. using Random Amplified Polymorphic DNA (RAPD) markers. International Food Research Journal 20(2): 919-923.

Doyle JJ, Doyle JL (1990) Isolation of plant DNA from fresh tissue. Focus 12:13-15

Garris AJ, Tai TH, Coburn J, Kresovich S, McCouch SR (2005) Genetic structure and diversity in Oryza sativa L. Genetics 169: 1631-1638.

Hadrys I-I, Balick M and Schier Water B (1992) Applications of random amplified polymorphic DNA (RAPD) in molecular ecology. Molec. Ecol. 1: 55-63.

Hossain M and Jaim WMH (2009) Diversity and diffusion of rice varieties: A data base for Bangladesh. Report submitted to IFPRI, Harvest Plus Project, July.

Krisoks' Weblog 2012 (https://farmersvoice.wordpress.com/2012/02/16/double-grainedrice-in-bangladesh/)

Maclean JL, Dawe DC, Hardy B and Hettel GP (2002) Rice Almanac. Source Book for the Most Important Economic Activity on Earth. Third edition. Wallingford, UK: CABI Publishing.

Malik AR, Zahida HP and Muhammad SM (2008) Genetic diversity analysis of traditional and improved cultivars of Pakistani rice (Oryza sativa L.) using RAPD markers. Electronic Journal of Biotechnology 11(3): 1-10.

Moghaieb REA, Mohammed Etr HK and Youssief SS (2014) Genetic diversity among some canola cultivars as revealed by RAPD, SSR and AFLP analyses. Biotech 4: 403410.

Muhammad A, Samina K, Muhammad AB, Anjuman A and Yusuf Z (2005) Genetic diversity among rice genotypes of Pakistan through Random Amplified Polymorphic DNA (RAPD) analysis. Pakistan J. Bot. 37(3): 585-592. 
RAPD Profile Analysis of Single and Multigrain Aman Rice

Nei M 1972. Genetic distance between populations. Amer. Nat. 106: 283-292.

Nimbal S, Behl RK and Chhabra AK (2009) RAPD analysis for genetic polymorphism in bread wheat (Triticumae stivum L. em Thell) genotypes varying for grain protein content. The South Pacific J. Natural Science 27: 49-56.

Paranthaman R, Alagusundaram K and Indhumathi J 2009. Production of protease from rice mill wastes by Aspergillus niger in solid state fermentation. World Journal of Agricultural Sciences 5: 308-312.

Rahman SN, Islam MS, Alam MS and Nasiruddin KM (2007) Genetic polymorphism in rice (Oryza sativa L.) through RAPD analysis. Indian J. Biotechnol. 6: 224-229.

Ravi M, Geethanjali S, Sameeyafarheen F, Maheswaran M (2003) Molecular marker based genetic diversity analysis in rice (Oryza sativa L.) using RAPD and SSR. Euphytica 133: 243-252.

Redoña ED and Mula LG (2004). Some imperatives and challenges for rice biotechnology in Asian national agricultural research and extension systems. Asian Biotechnol Dev Rev 71: 9-38.

Salim M, Akram M, Akhtar ME and Ashraf M (2003) Rice, A production Hand Book. Pakistan Agricultural Research Council, Islamabad. p. 70.

Saxena B, Kaur R and Bhardwaj SV (2011) Assessment of genetic diversity in cabbage cultivars using RAPD and SSR markers. Journal of Crop Science and Biotechnology 14: 191-196.

Singh AK, Kumar R, Pareek A, Sopory SK and Singla-Pareek SL (2012) Overexpression of rice CBS domain containing protein improves salinity, oxidative, and heavy metal tolerance in transgenic tobacco. Mol. Biotech. 52: 205-216.

Sun ZR, Ni PC and Hung ZZ (1990) Studies on the analysis of variance and major/minor factors of medium components influencing the efficiency of callus production ability. Acta Argon. Sin. 16: 123-130.

Tautz D (1989) Hypervariability of simple sequence as a general source for polymorphic DNA markers. Nuc. Acids Res. 17: 6463-6471.

Thomson MJ, Septiningsih EM, Suwardjo F, Santoso TJ, Silitonga TS and McCouch SR (2007) Genetic diversity analysis of traditional and improved Indonesian rice (Oryza sativa L.) germplasm using microsatellite markers. Theor. Appl. Genet. 114: 559-568.

Tyagi A, Khurana JP, Khurana P, Raghuvanshi S, Gaur A, Kapur A, Gupta V, Kumar D, Ravi V, Vij S, Khurana P and Sharma S (2004) Structural and functional analysis of rice genome. J. Genet. 83: 79-99.

Vos P, Hogers R, Bleeker M, Reijans M, van de Lee T, Hornes M, Frijters JP, Peleman J, Kuiper M and Zabeau M (1995) AFLP: A new fingerprinting technique for DNA fingerprinting. Nucleic Acids Res. 23: 4407-4414

Williams JGK, Kubelik AR, Livak KJ, Reafalski JA and Tingey SV (1990) DNA polymorphisms amplified by arbitrary primers are useful as genetic markers. Nucleic Acids Research 18: 6531-6535.

Yeasmin S, Islam MM and Begum SN (2013) Molecular characterization of some rice genotypes using RAPD markers. Bangladesh J. Nuclear Agric. 29: 1-11. 